\title{
Preliminary Evidence Of SFAS No. 130's Effect On Gains Trading In The Insurance Industry
}

Charles E. Jordan (Email: Jordan@cba.usm.edu), University of Southern Mississippi Stanley J. Clark (Email: Clark@ cba.usm.edu), University of Southern Mississippi Mary H. Anderson (Email: Wander7816@aol.com), Louisiana Tech University

\begin{abstract}
Gains trading represents a form of earnings management whereby appreciated marketable securities are sold at a gain while those with a loss are retained. By not requiring unrealized gains and losses on available-for-sale securities to flow through income, SFAS No. 115 failed to close the door on this type of earnings management. With SFAS No. 130, however, these unrealized gains and losses must now be reported prominently in a financial statement as a component of comprehensive income. By examining the level of gains trading for a sample of companies in the insurance industry both before and after the implementation of SFAS No. 130, the current study provides evidence suggesting that this form of earnings management subsided subsequent to the adoption of SFAS No. 130.
\end{abstract}

\subsection{Introduction}

$E$ arnings management has always represented an issue worth investigating. However, with the failure of Enron and the debacle of Andersen, earnings management studies take on even more significance. In 1998 in what seems today like an almost prophetic statement, then SEC chairman Arthur Levitt vigorously attacked earnings management and noted that such accounting "hocus-pocus" represents "a serious threat to the viability of the financial reporting that underpins the U.S. capital markets (Duncan, 2001, p. 33). Even though no standard definition exists for earnings management, Beattie et al. (1994, p. 792) state that it is a "process of taking deliberate steps within the constraints of generally accepted accounting principles to bring about a desired level of earnings." Determining income under an accrual basis accounting system requires numerous discretionary judgments by management, and this discretion allows earnings to be swayed in either direction. One such discretionary decision involves the timing on the sale of assets. LeGrand (1993, p. 46) notes that a common form of earnings management is gains trading, which is "the practice of selling appreciated assets [securities] at a gain while retaining those at a loss." The end result is an improvement in current earnings.

Effective in 1998, Statement of Financial Accounting Standards (SFAS) No. 130, Reporting Comprehensive Income, began requiring companies to report comprehensive income and its components. One of these components represents unrealized holding gains and losses on securities classified as available for sale (AFS). Only realized gains and losses on these securities impact traditional earnings; however, the unrealized gains and losses affect comprehensive income and must be reported in a financial statement given equal prominence with other financial statements. Thus, an important question for the Financial Accounting Standards Board (FASB) and the financial community concerns whether SFAS No. 130 and its required reporting of unrealized gains and losses created any apparent effect on the level of earnings management with respect to gains trading of AFS securities. This article addresses this question.

Readers with comments or questions are encouraged to contact the authors via email. 


\subsection{Literature Review}

The literature reviewed for this study centers around two relevant streams of research. First, earnings management studies are examined, and, second, studies relating to the reporting of comprehensive income under SFAS No. 130 are considered.

\subsection{Earnings Management Literature}

Numerous studies exist concerning earnings management. Some studies explain why earnings management occurs. For example, Duncan (2001) identifies 20 pressures that can drive management to manipulate earnings. These pressures come from sources both inside and outside the company. One such pressure is the need to meet analysts' forecasts of earnings. Failure to meet earnings estimates can result in sharp declines in share price. Collingwood (2001) and Parfet (2000) also note that managers face extreme pressure to meet analysts' expectations of a smooth, steady rise in earnings. As a case in point, Collingwood (2001) states that Cisco Systems was a Wall Street favorite for several quarters because the company had for 14 consecutive quarters exceeded analysts' earnings forecasts by a penny per share. In the second quarter of Cisco's 2001 fiscal year, however, the company reported earnings that fell 1 cent short of the consensus estimate of $\$ .19$ per share. The market promptly punished Cisco the next day as its share price dropped 13 percent.

Another stream of earnings management research discusses the methods that can be used to manage earnings. For example, Bauman et al. (2001) and Choi et al. (2001) examine earnings management with respect to judgments concerning the valuation allowance for deferred tax assets and the alternative minimum tax, respectively. In a broader study, Jackson and Pitman (2001) identify several ways earnings can be managed. Some of these involve management's discretion regarding accounting estimates (e.g., estimates concerning the collectibility of receivables or warranty obligations). Others involve management's discretion regarding the timing of transactions, such as the act of cherry picking or gains trading on the sale of securities. It is this area of earnings management that is of particular concern in the current study.

Barth and Collins (1994) note that SFAS No. 115, Accounting for Certain Investments in Debt and Equity Securities, fell short of eliminating management's ability to engage in gains trading with respect to AFS securities by not requiring unrealized gains and losses on these securities to pass through earnings. Under SFAS No. 115, these unrealized gains and losses affect equity, but not earnings. A study by Jordan et al. (1997/1998) provides direct evidence of gains trading subsequent to SFAS No. 115. Their study showed that, for a sample of companies in the insurance industry, the amount of net realized gains on AFS securities was related to certain financial characteristics of the firms studied. The current study seeks to examine whether the level of gains trading observed in the pre-SFAS No. 130 project by Jordan et al. (1997/1998) appears to have been affected by the reporting of comprehensive income and its components under SFAS No. 130.

\subsection{Comprehensive Income Literature}

SFAS No. 130 now requires companies with certain types of unrealized gains and losses to report these items in comprehensive income (CI). Such unrealized gains and losses are known as items of other comprehensive income (OCI). The most common OCI item is unrealized gains and losses on securities classified as AFS. In essence, $\mathrm{CI}$ for a period is net income plus or minus the items of OCI. Companies may report CI and its components in one of the following ways:

1. In a separate statement of comprehensive income.

2. In a combined statement of income and comprehensive income.

3. In a statement of changes in stockholders' equity.

The first two reporting formats result in CI being displayed as a performance-based measure, while the third format presents CI as a nonperformanced-based measure. The FASB believes CI is a measure of financial performance 
and, as such, recommends either of the first two reporting options. The FASB allows the third format, however, because of heavy opposition it received from corporate America during the exposure draft phase of the standard.

A significant portion of the research on SFAS No. 130 has centered on determining which format companies use to report $\mathrm{CI}$ and whether relationships exist between the format chosen and financial characteristics of the firms selecting them. For example, Campbell et al. (1999) examined 73 early adopters of SFAS No. 130 and found that 53 percent of them opted to report CI in a statement of changes in stockholders' equity (SCSE). They also discovered that firms reporting materially positive amounts of OCI were prone to report CI in a performancebased financial statement while firms with immaterial or negative amounts of OCI tended to report CI in a SCSE. Jordan and Clark (2002) examined the reporting format for 100 financial service firms and found that 63 percent of them chose to report CI in a SCSE. Similar to Campbell et al. (1999), Jordan and Clark (2002) found that a relationship existed between the reporting format chosen and the size or direction of the items of OCI. Companies with negative or small amounts of OCI tended to report CI in a SCSE.

Ketz (1999) examined CI reporting for 90 large companies and stated that the majority of them presented $\mathrm{CI}$ in a SCSE. He did not examine relationships between the size or direction of the OCI items and the reporting format chosen. Finally, Bhamornsiri et al. (2001) studied CI reporting for the Fortune 100 companies and found that 76 percent of them reported CI in a SCSE. They tested for relationships between the size or direction of the OCI items and the reporting format used and concluded that no significant relationships existed. Thus, all studies found that the majority of companies report $\mathrm{CI}$ in a nonperformance-based financial statement, yet their results are mixed concerning whether the format decision seems to be related to the size or direction of the OCI items being reported.

Another relevant stream of CI research addresses the perceived usefulness of the reporting formats. In a survey of financial analysts, King et al. (1999) found that the use of CI by this group would be affected by where CI is reported. Analysts indicated that they would be less likely to use CI in the computation of traditional performance measures if it is reported in a SCSE. In a study involving nonprofessional investors, Maines and McDaniel (2000) concluded that this group of users also did not consider CI to be a measure of performance if it is reported in a SCSE. Hirst and Hopkins (1998) present important findings for the current study. Their research, conducted prior to the implementation of SFAS No. 130, involved an experiment with financial analysts to determine if "CI reporting - as required by SFAS No. 130 - influences analysts' estimates of the value of a company that actively manages earnings through its AFS securities portfolio (Hirst and Hopkins, 1998, p. 48)." Hirst and Hopkins concluded that displaying unrealized gains and losses on AFS in a SCSE was not as effective as displaying them in an income statement format for purposes of enhancing the transparency of a company's earnings management with regard to gains trading in its investment portfolio.

The literature on reporting CI clearly shows that the majority of companies report it in a SCSE. Some evidence also exists suggesting that the size or direction of the items of OCI may impact the CI reporting format chosen. That is, the decision regarding the reporting format used may be outcomes related and affected by management's desire to manipulate the financial statement presentation to a certain degree. Finally, strong evidence exists suggesting that reporting CI in a SCSE provides less useful information for investors than presenting it in a performance-based financial statement. Thus, the reporting format used may indicate a certain mindset of management. Management that reports CI in a performance-based format may be attempting to increase the transparency of the earnings effects of its AFS securities, while management that reports CI in a SCSE may be less concerned about improving this earnings transparency. The current study examines whether the extent of gains trading with respect to sales of AFS securities differs between companies reporting CI in a performance-based versus a nonperformance-based financial statement.

\subsection{Methodology}

The literature review revealed two related questions with respect to gains trading and SFAS No. 130. First, previous research showed that gains trading or earnings management with respect to realized gains on AFS securities occurred in the insurance industry prior to SFAS No. 130. The question raised here is whether the reporting of unrealized gains and losses on AFS securities in CI as required by SFAS No. 130 seems to have 
impacted the level of gains trading in the insurance industry. Second, prior studies have shown that the transparency of unrealized gains and losses on AFS securities in relation to their effect on the financial performance of a firm is affected by where these items of OCI are reported in the financial statements. Reporting the items of OCI in a SCSE impedes their usefulness. In addition, previous research suggests that the decision regarding where to report CI and the items of OCI may be related to the size or direction of the unrealized gains and losses on AFS securities. The question raised here is whether the level of gains trading subsequent to SFAS No. 130 differs between companies reporting $\mathrm{CI}$ in a performance-based versus a nonperformance-based financial statement.

To answer these questions, the Jordan et al. (1997/1998) study, which tested for gains trading in the insurance industry a few years prior to SFAS No. 130, is replicated where applicable. They developed ordinary least squares regression models with the dependent variables representing measures of gains trading. One of their dependent variables, and the one used in the current study, is:

Net realized gains to AFS securities (GAINS) - Represents the ratio of the period's net realized gains on AFS securities (i.e., realized gains minus realized losses) to the year-end balance of AFS securities. This variable provides a relative measure of the amount of gains trading that occurred during the period; higher values suggest more active gains trading.

The model was developed to test the idea that companies with certain financial characteristics might be more prone to manage earnings through gains trading than other companies without these same characteristics. The independent variables represented measures of a company's need to manage earnings. The three independent variables used in the Jordan et al. (1997/1998) study are also used here. These variables are:

Return on assets (ROA) - Represents the period's income before taxes and realized gains and losses on sales of AFS securities to total assets. This variable provides a measure of the current earnings level and, as such, the need to engage in gains trading. Firms with relatively low ROAs would seem more likely to engage in gains trading to improve their earnings levels than would firms with relatively high ROAs.

Leverage (LEV) - Represents the ratio of total year-end liabilities to total year-end assets. Most companies enjoy positive financial leverage. That is, they earn a higher return on their assets than they have to pay in interest to finance those assets. Employing debt in the presence of positive financial leverage enhances a company's earnings level. Thus, a company using a heavier amount of debt may have less need to manage its earnings through gains trading because its earnings are already being boosted by the excess returns resulting from the positive financial leverage.

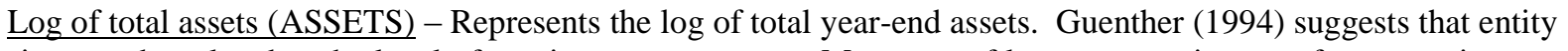
size may be related to the level of earnings management. Managers of large companies may face more intense pressure to achieve earnings levels than managers of small companies. Thus, managers of large companies may be more inclined to engage in gains trading. The log of total assets was used rather than absolute asset size because the latter amount is typically not normally distributed. Logging the asset size is a common means of normalizing this variable without sacrificing its explanatory power.

To determine if SFAS No. 130 impacted the level of gains trading on AFS securities, a sample of 100 randomly selected companies in the insurance industry was obtained. The insurance industry was chosen for study for three reasons. First, previous research provided evidence that gains trading existed in this industry prior to SFAS No. 130. Second, firms in this industry maintain significant holdings of AFS securities and, therefore, have ample opportunity to engage in gains trading. Third, because of the significant presence of AFS securities, virtually every firm in this industry would have unrealized gains and losses and, thus, would need to report CI and its components in conformity with SFAS No. 130.

Even though Jordan et al. (1997/1998) provided evidence that gains trading existed in their 1995 (preSFAS No. 130) sample of insurance companies, it could not be assumed that the same would hold true for the sample of companies in the current study. To determine if the companies in this study engaged in gains trading prior 
to SFAS No. 130, data were collected and models were developed for 1997 (i.e., the year just prior to the implementation of SFAS No. 130). To determine if the level of gains trading changed subsequent to SFAS No. 130's adoption, data were collected for the same 100 firms and models were developed for 1998 (i.e., the first year after implementation of SFAS No. 130). All data were collected from the SEC's EDGAR database. Models were developed for the overall sample of 100 companies, and separate models were developed for the sample split into subgroups according to how the firms reported CI (i.e., in either a performance-based or a nonperformance-based financial statement).

\subsection{Results}

The majority (67) of the 100 companies in the sample opted to report CI in 1998 in a nonperformancebased financial statement (i.e., a SCSE). Only 33 firms presented CI in a performance-based financial statement (i.e., either a separate comprehensive income statement or a combined statement of net income and comprehensive income). This result was not surprising and echoes the findings of earlier studies. Also, the ratio of 1998 net unrealized holding gains (i.e., unrealized gains minus unrealized losses) to 1998 AFS securities was compared between the two groups to determine if the level of net unrealized gains differed between them. Consistent with the results of Campbell et al. (1999) and Jordan and Clark (2002), the companies presenting the unrealized gains and losses in a performance-based statement reported, in general, larger amounts of net unrealized gains than did their counterparts using a SCSE. The former group had a median 1998 net unrealized gains to AFS securities of .852 percent, while the latter group produced a median of .463 percent. Medians were used as summary measures rather than means because means can be unduly influenced by a few extreme observations; medians are much less affected by these outlying values. A sign test revealed that the medians differed between the two groups at an alpha level of .001 .

Table 1 presents the regression results for the 1997 (pre-SFAS No. 130) data for the entire sample of 100 companies and for the two subsamples separated by the choice of reporting format for CI. Even though CI was not reported in 1997, these two groups were separated in 1997 so that comparisons could be made with their regression results in 1998. In addition, any management mindset that existed in 1998 likely also existed in 1997, and the companies within each of the two subgroups are probably more homogeneous that are the companies in the entire sample.

For the entire sample, Table 1 clearly indicates that the level of net realized gains reported in 1997 is related to the financial characteristics of the firms. The coefficients for ROA and LEV both produce statistically significant t-statistics and possess the hypothesized signs (i.e., both are negative). A negative coefficient for ROA implies that firms with lower levels of pre-gain earnings are more likely to engage in gains trading. A negative coefficient for LEV suggests that firms using lower levels of debt leverage are more likely to engage in gains trading. The boost to their earnings from gains trading may offset the loss of earnings they may be experiencing because they are using less financial leverage to generate income. The coefficient for ASSETS for the entire sample is insignificant; however, it does possess the correct sign (i.e., it is positive). That is, management of larger companies would be more likely to engage in gains trading because of the intense pressure they face to perform. The F-statistic shows that, overall, the 1997 entire-sample model is significant at a .046 alpha level, which indicates that gains trading occurred for this sample of firms prior to SFAS No. 130.

Table 1 also presents the 1997 regression results for the 67 companies that chose a nonperformance-based reporting format for CI in 1998. The summary statistics for this subsample are similar to the results for the overall sample. The coefficients for ROA and LEV are statistically significant and correctly signed. The coefficient for ASSETS, although correctly signed, is statistically insignificant. The model itself is significant by traditional standards (i.e., it possesses an F-statistic with an alpha level of .079), which suggests that gains trading for this group of companies occurred prior to SFAS No. 130. 
Table 1: Summary Statistics for Pre-SFAS No. 130 Regression Models

\begin{tabular}{|c|c|c|c|c|c|c|}
\hline $\begin{array}{l}\text { Independent } \\
\text { Variable }\end{array}$ & $\underline{\text { Coefficient }}$ & $\underline{\text { t-statistic }}$ & $\mathrm{p}>\mathrm{t}$ & $\begin{array}{l}\text { Model } \\
\text { F-statistic }\end{array}$ & $\mathrm{p}>\mathrm{F}$ & $\begin{array}{l}\text { Model adj. } \\
\text { R-square }\end{array}$ \\
\hline \multicolumn{7}{|c|}{ Entire sample (100 companies): } \\
\hline Intercept & 3.1311 & 1.84 & .068 & & & \\
\hline ROA & -.0937 & -2.38 & .019 & & & \\
\hline LEV & -.0326 & -2.23 & .028 & & & \\
\hline ASSETS & .0287 & 0.24 & .814 & 2.77 & .046 & .052 \\
\hline \multicolumn{7}{|c|}{ Nonperformance-based subsample (67 companies): } \\
\hline Intercept & 2.8828 & 1.25 & .215 & & & \\
\hline ROA & -.1044 & -2.15 & .035 & & & \\
\hline LEV & -.0479 & -2.18 & .033 & & & \\
\hline ASSETS & .1288 & 0.72 & .473 & 2.37 & .079 & .060 \\
\hline \multicolumn{7}{|c|}{ Performance-based subsample (33 companies): } \\
\hline Intercept & 2.7566 & 1.48 & .151 & & & \\
\hline ROA & -.0308 & -0.40 & .693 & & & \\
\hline LEV & -.0083 & -0.64 & .526 & & & \\
\hline ASSETS & -.0866 & -0.81 & .425 & 0.37 & .777 & .000 \\
\hline
\end{tabular}

Note: The dependent variable for each model was the net realized gains to AFS securities.

The third 1997 regression model presented in Table 1 is for the group of companies that reported CI in 1998 in a performance-based financial statement. Notice that none of the independent variables are individually significant; furthermore, the alpha level for the model's F-statistic reveals that the model itself is statistically insignificant. Interestingly, this group of companies appears not to have been engaged in gains trading, at least as measured by the variables in this study. Although there is no way of determining or knowing why this group apparently did not engage in gains trading, one possible explanation is that it may have had no need to do so. That is, maybe the firms in this group enjoyed pre-gain earnings that were significantly larger than those of the nonperformance-based group and, thus, no earnings management was deemed necessary. The median ROA for the performance-based group of 3.08 percent, indeed, exceeded the median ( 2.40 percent) for the nonperformance-based group. However, a sign test revealed that the medians did not differ between the groups at a statistically significant level (i.e., an alpha level of .243).

Another possible reason the performance-based group did not engage in gains trading in 1997 could relate to the mindset of management. This group of managers chose in 1998 to report CI and the items of OCI in a format preferred by the FASB. They made a conscious decision to report their unrealized gains and losses in 1998 in a performance-based statement, which as prior research has shown enhances the usefulness and transparency of the CI information. This action may reveal a desire by managers in this group to report financial results that are free from bias and clutter. If this is the mindset of the performance-based group, then one would perceive them to be less likely to engage in gains trading to manage earnings than the group of managers who chose to present CI in a SCSE. Although such a notion could not be tested empirically, it represents a plausible explanation concerning why the group reporting CI in a performance-based statement did not appear to engage in gains trading in 1997.

Table 2 presents the results for the models developed with post-SFAS No. 130 data (i.e., with 1998 data). Notice that the t-statistics for every independent variable in each of the three models proved to be statistically insignificant. In addition, the F-statistics for each model in general demonstrated that all three models were statistically insignificant. These results were not surprising for the subsample of companies that reported CI in a performance-based financial statement. These companies did not engage in gains trading prior to SFAS No. 130; thus, there was no reason to believe they would do so after its implementation. 
Table 2: Summary Statistics for Post-SFAS No. 130 Regression Models

\begin{tabular}{|c|c|c|c|c|c|c|}
\hline $\begin{array}{l}\text { Independent } \\
\text { Variable } \\
\end{array}$ & $\underline{\text { Coefficient }}$ & $\underline{\text { t-statistic }}$ & $\mathrm{p}>\mathrm{t}$ & $\begin{array}{l}\text { Model } \\
\text { F-statistic }\end{array}$ & $\mathrm{p}>\mathrm{F}$ & $\begin{array}{l}\text { Model adj. } \\
\text { R-square }\end{array}$ \\
\hline \multicolumn{7}{|c|}{ Entire sample (100 companies): } \\
\hline Intercept & 2.2565 & 0.46 & .645 & & & \\
\hline ROA & -.1428 & -1.53 & .129 & & & \\
\hline LEV & -.0778 & -1.56 & .122 & & & \\
\hline ASSETS & .3105 & 0.85 & .346 & 1.10 & .351 & .003 \\
\hline \multicolumn{7}{|c|}{ Nonperformance-based subsample (67 companies): } \\
\hline Intercept & .7360 & 0.11 & .912 & & & \\
\hline ROA & -.1891 & -1.45 & .151 & & & \\
\hline LEV & -.0928 & -1.30 & .198 & & & \\
\hline ASSETS & .4870 & 0.88 & .381 & 0.90 & .447 & .000 \\
\hline \multicolumn{7}{|c|}{ Performance-based subsample (33 companies): } \\
\hline Intercept & 3.2680 & 1.53 & .136 & & & \\
\hline ROA & .0001 & 0.00 & .999 & & & \\
\hline LEV & -.0333 & -1.51 & .142 & & & \\
\hline ASSETS & .0026 & 0.02 & .984 & 1.21 & .325 & .019 \\
\hline
\end{tabular}

Note: The dependent variable for each model was the net realized gains to AFS securities.

The most interesting finding revealed in Table 2 is that the models for the entire sample and the subsample of companies reporting CI in a SCSE proved to be statistically insignificant in 1998. Obviously, the entire-sample model produces results similar to the model for the SCSE group because the latter group comprises such a heavy portion (i.e., 67 percent) of the companies in the entire sample. Thus, the key finding here is that the SCSE group did not appear to engage in gains trading in 1998 with respect to its AFS securities. More specifically, this group engaged in gains trading prior to SFAS No. 130 but did not do so after its implementation.

These results provide evidence that SFAS No. 130 may have curtailed the amount of gains trading with respect to investment securities. As Brauchle and Reither (1997) note, a major objective of SFAS No. 130 was to provide a transparent display of CI and its components. These authors, both associated with the FASB at the time, noted that increased transparency of the unrealized gains and losses affecting CI should result regardless of the format used to report CI. Even if CI is reported in a SCSE, they point out that the information on unrealized gains and losses will be communicated more effectively to users than before SFAS No. 130 because the information must be provided not in the footnotes but in a statement given equal prominence with other financial statements. Perhaps this increased transparency of the unrealized gains and losses subsequent to SFAS No. 130 led management to engage in less gains trading to manage earnings. If so, then SFAS No. 130 seems to have improved the financial reporting process as the FASB intended.

These results do not prove definitively that gains trading lessened because of the increased transparency required by SFAS No. 130 as other factors could have driven the findings. For example, it is possible that the firms had more need to manage earnings in 1997 than they did in 1998. Reviewing the pre-gain ROAs for the SCSE group, however, suggested that gains trading would have been more likely to occur in 1998 than in 1997. More specifically, the median pre-gain ROAs for this group for 1998 and 1997 were 1.30 percent and 2.40 percent, respectively. A sign test revealed that the median pre-gain ROAs differed between the two years at a statistically significant level (i.e., an alpha level of .002). Since the 1998 pre-gain ROAs were significantly less than the 1997 pre-gain ROAs for the SCSE group as a whole, gains trading in 1998 to improve earnings would have seemed likely, but this did not occur. The debt leverage (LEV) variables for the SCSE group differed very little between 1998 and 1997, with medians of 77.77 percent and 76.13 percent, respectively. A sign test revealed that these medians did not differ by a statistically significant amount (i.e., an alpha level of .195). Thus, the decline observed in the level of 
gains trading between 1997 and 1998 in the regression models did not occur due to changes in the debt leverage for the firms.

It is also possible a higher level of gains trading occurred in 1997 than in 1998 for the SCSE group because there may have been more opportunity to trade on gains in 1997 than in 1998. An examination of the data, however, revealed that the vast majority of companies in both years reported net unrealized holding gains (i.e., their unrealized gains on AFS securities exceeded their unrealized losses). Thus, it appears that the firms had ample opportunity to "cherry pick" their appreciated securities and engage in gains trading in both years. For some reason, though, the models in this study suggest that significantly less gains trading occurred in 1998 than in 1997. One explanation could simply be that management felt less need to gains trade in 1998 than in 1997 because the unrealized gains and losses in 1998 were prominently displayed in a financial statement for all to see. There may have been little perceived need to sell appreciated securities to realize the gains because of the increased transparency of the unrealized gains and losses required by SFAS No. 130.

\subsection{Summary and Conclusion}

Prior research has shown that gains trading occurred in the insurance industry in relation to selling AFS securities. With SFAS No. 130, the FASB hoped to increase the transparency of financial reporting with respect to certain items that the Board felt affected the financial performance of a company. One such item is the unrealized gains and losses on AFS securities. Before SFAS No. 130, these unrealized gains and losses affected the stockholders' equity of a company, but their effects could be buried in the footnotes. After SFAS No. 130, these unrealized gains and losses still affect equity and not traditional earnings; however, their effects must be prominently displayed in the financial statements as a component of CI.

This study sought to determine if this increased exposure of the unrealized gains and losses under SFAS No. 130 might impact the level of gains trading in the insurance industry. For the sample of companies reporting CI and its components in a SCSE, the results provide evidence of significant gains trading prior to SFAS No. 130 (i.e., in 1997). In the first year after SFAS No. 130's implementation (i.e., 1998), however, these same firms engaged in insignificant levels of gains trading as measured by the model in this study. Did this decrease in gains trading occur because of the increased transparency of reporting unrealized gains and losses required by SFAS No. 130? There is no way of truly knowing the answer to this question as unforeseen or unknown factors may have caused the decline in the level of gains trading, but certainly the increased reporting requirements of SFAS No. 130 provide one plausible explanation. If the decrease in gains trading is, indeed, attributable to the increased reporting transparency under SFAS No. 130, then the standard seems to have provided a needed improvement in the overall financial reporting model by reducing the level of earnings management.

In addition, the results of the study demonstrate that, prior to SFAS No. 130, firms acted inconsistently with regard to their levels of gains trading. More specifically, the nonperformance-based group engaged in significant gains trading prior to SFAS No. 130, while the performance-based group did not. Subsequent to SFAS No. 130, neither group seemed to engage in significant levels of gains trading. Thus, it appears that the consistency of financial reporting among firms may have improved following the implementation of SFAS No. 130.

\subsection{Suggestions for Future Research}

This study provides evidence indicating that gains trading curtailed subsequent to the implementation of SFAS No. 130. The study does not demonstrate, however, that gains trading declined necessarily as a result of SFAS No. 130. Future research could expand on this study to provide additional evidence either supporting or refuting such a causal relationship. The models in future studies could be developed for multiple years prior to and subsequent to the implementation of SFAS No. 130. For example, if individual models for the three years prior to SFAS No. 130 consistently demonstrated significant levels of gains trading while models for the three years following SFAS No. 130 consistently showed insignificant levels, strong evidence would exist that gains trading subsided as a result of SFAS No. 130. 
Arguments for such a causal relationship could also be strengthened by replicating the current study in a different industry. This study examined firms in the insurance industry because of the prevalence of AFS securities for companies in this industry. Another industry greatly affected by AFS securities and their unrealized gains and losses would be the financial services industry. Declining levels of gains trading subsequent to SFAS No. 130 for financial service firms would provide additional support for the notion that the standard produced a positive effect on earnings management.

\section{References}

1. Barth, M.E. and D.W. Collins, "Response to the exposure draft Accounting for Certain Investments in Debt Securities," Accounting Horizons, Vol. 8, No. 2, pp. 117-119, 1994.

2. Bauman, C.C., P.P. Bauman, and R.F. Halsey, "Do firms use the deferred tax asset valuation allowance to manage earnings?," The Journal of the American Taxation Association, Vol. 23, supplement, pp. 27-48, 2001.

3. Beattie, V., S. Brown, D. Ewers, J. Brian, S. Manson, D. Thomas, and M. Turner, "Extraordinary items and income smoothing: a positive accounting approach," Journal of Business Finance \& Accounting, Vol. 21, No. 6, pp. 791-811, 1994.

4. Bhamornsiri, S., C. Wiggns, and R.H. Colson, "Comprehensive income disclosures," CPA Journal, Vol. 71, No. 10, pp. 54-56, 2001.

5. Brauchle, G.J. and C.L. Reither, "SFAS No. 130: reporting comprehensive income," CPA Journal, Vol. 67. No. 10, pp. 42-46, 1997.

6. Campbell, L., D. Crawford, and D. Franz, "How companies are complying with comprehensive income disclosure requirements," The Ohio CPA Journal, Vol. 58, No. 1, pp. 13-20, 1999.

7. Choi, W.W, J.D. Gramlich, and J.K. Thomas, "Potential errors in detecting earnings management: reexamining studies of the AMT," Contemporary Accounting Research, Vol. 18, No. 4, pp. 571-613, 2001.

8. Collingwood, H., "The earnings game," Harvard Business Review, Vol. 79, No. 6, pp. 65-72, 2001.

9. Duncan, J.R., "Twenty pressures to manage earnings," CPA Journal, Vol. 71, No. 7, pp. 33-37, 2001.

10. Guenther, D., "Earnings management in response to corporate tax rate changes: evidence from the 1986 Tax Reform Act," The Accounting Review, Vol. 69, No. 1, pp. 230-243, 1994.

11. Hirst, D.E. and P.E. Hopkins, "Comprehensive income reporting and analysts' valuation judgments," Journal of Accounting Research, Vol. 36, supplement, pp. 47-75, 1998.

12. Jackson, S.B. and M.K. Pitman, “Auditors and earnings management," CPA Journal, Vol. 71, No. 7, pp. 39-44, 2001.

13. Jordan, C.E. and S. J. Clark, "Comprehensive income: how is it being reported and what are its effects?," Journal of Applied Business Research, Vol. 18, No. 2, pp. 1-8, 2002.

14. Jordan, C.E., S.J. Clark, and W.R. Smith, "Earnings management under SFAS No. 115: evidence from the insurance industry," Journal of Applied Business Research, Vol. 14, No. 1, pp. 49-56, 1997/1998.

15. Ketz, E.J., "Comprehensive income: what do the numbers disclose?," The Journal of Corporate Accounting and Finance, Vol. 10, No. 4, pp. 79-96, 1999.

16. King, T.E., A.K. Ortegren, and B.J. Reed, "An analysis of the impact of alternative financial statement presentations of comprehensive income," Academy of Accounting and Financial Studies Journal, Vol. 3, No. 1, pp. 19-42, 1999.

17. LeGrand, J.E., "Singing a mark-to-market song," Bankers Magazine, Vol. 176, No. 6, pp. 46-49, 1993.

18. Maines, L.A. and L.S. McDaniel, "Effects of comprehensive income characteristics on nonprofessional investors' judgments: the role of financial statement presentation format," Accounting Review, Vol. 75, No. 2, pp. 179-207, 2000.

19. Parfet, W.U., "Accounting subjectivity and earnings management: a preparer perspective," Accounting Horizons, Vol. 14, No. 4, pp. 481-488, 2000. 
Notes 